\title{
The enabled homolog gene polymorphisms are associated with susceptibility and progression of childhood IgA nephropathy
}

\author{
Won-Ho Hahn, Jin-Soon Suh, \\ Byoung-Soo Cho and Sung-Do Kim ${ }^{1}$
}

\author{
Department of Pediatrics \\ East West Kidney Diseases Research Institute \\ Kyung Hee University Hospital \\ Seoul 130-701, Korea \\ ${ }^{1}$ Corresponding author: Tel, 82-2-958-8295; \\ Fax, 82-2-967-1382; E-mail, kimsungdo@khu.ac.kr \\ DOI 10.3858/emm.2009.41.11.085
}

Accepted 29 June 2009

Abbreviations: $\mathrm{Cl}$, confidence interval; $E N A H$, enabled homolog gene; IgAN, IgA nephropathy; LD, linkage disequilibrium; OR, odds ratio; SNP, single nucleotide polymorphism

\begin{abstract}
The enabled homolog gene (ENAH, hMena) is abundantly expressed in mesangial tissue, and might play an important role in inflammatory processes of $\lg A$ nephropathy (IgAN). The present study was conducted to investigate the association between single nucleotide polymorphisms (SNPs) of the ENAH and childhood IgAN. We analyzed 12 SNPs of ENAH in 176 patients with childhood IgAN and 397 healthy controls. In addition, IgAN patients were dichotomized and compared with respect to several clinical and pathological parameters. Genotyping data showed significant differences between IgAN patients and controls in the frequency of rs2039620, rs12034829, and rs3795443. On comparison of patients with proteinuria to those without proteinuria ( $\leq$ or $>4 \mathrm{mg} / \mathrm{m}^{2} / \mathrm{h}$ ), rs 12043633 was significantly different between the two groups. With regard to maximum proteinuria ( $\leq$ or $>4 \mathrm{mg} / \mathrm{m}^{2} / \mathrm{h}$ ), rs3795443, rs4653643, rs6751, rs10799319, rs7555139, rs576861, and rs487591 showed significant allele frequency differences. For patients with and without gross hematuria, rs4653643, rs6751, rs10799319, rs7555139, rs576861, and rs 487591 showed significant allele frequency differences. The rs 3795443 was found to be associated with progression of pathological findings. Our results suggest that ENAH polymorphisms are associated with increased susceptibility, development of proteinuria and gross hematuria, and pathological progression of childhood IgAN.
\end{abstract}

Keywords: Enah protein, human; glomerulonephritis, IGA; polymorphism, single nucleotide

\section{Introduction}

$\lg A$ nephropathy $(\lg A N)$ is the most common form of chronic glomerulonephritis in pediatric patients. The accumulation of $\lg A$ in the mesangium is the pathological hallmark of IgAN. The extent of the disease is correlated with mesangial cell proliferation and interstitial fibrosis, which lead to the development and progression of IgAN.

Recently, the enabled (Ena)/vasodilator-stimulated phosphoprotein (VASP) family has emerged as important in the regulation of cell motility, cell-tocell adhesion, and shape by virtue of their ability to promote actin polymerization and to form lamellipodia and filopodia at the leading edge of migrating cells (Bear et al., 2000; Krugmann et al., 2001; Krause et al., 2003; Boeda et al., 2007; Lindsay et al., 2007). They are components of adherens junctions, which are required for actin to dynamically seal membranes into epithelial sheets, in addition to control actin organization of cadherin adhesion contacts (Urbanelli et al., 2006; Di Modugno et al., 2007).

The Ena/VASP family includes three members: the enabled homolog gene (ENAH or human homologue of murine Mena; hMena), VASP, and EnaVASP-like $(E v l)$. These three vertebrate family members may provide overlapping functions. Each protein shares a similar tripartite domain that consists of an N-terminal Ena/VASP homology 1 (EVH1) domain and a variable central proline-rich region (FP4 motif), followed by a C-terminal Ena/ VASP homology 2 (EVH2) domain. The EVH1 domain plays a role in intracellular protein localization and is involved in the control of cell migration, by targeting the leading edge. The EVH2 domain, which contains both G- and F-actinbinding sites, is responsible for the regulation of actin polymerization. The central proline-rich domain mediates the interaction with proteins containing the $\mathrm{SH} 3$ and $\mathrm{WW}$ domains and with small actin monomer binding protein profiling (Boeda et al., 2007; Di Modugno et al., 2007).

After specific transmembrane signals are transduced by integrins, several focal adhesion pro- 
Table 1. Sequence of primers and conditions.

\begin{tabular}{|c|c|c|c|}
\hline SNP & & Sequence (5'-3') & Product size (bp) \\
\hline \multirow[t]{2}{*}{ rs3795443 } & Forward & TGGGCCTTGCCGAATTCAAGGGT & 513 \\
\hline & Reverse & CACATGAGTCCAGTGACTTCAGCA & \\
\hline \multirow[t]{2}{*}{ rs4653643 } & Forward & CAGGCCTACCAAGTTGATAGACCA & 507 \\
\hline & Reverse & ACTTGAGTCAAGCAAGCAGGAGCT & \\
\hline \multirow[t]{2}{*}{ rs1764345 + rs954534 } & Forward & CTCGATGAAGTGAAGAAGCCCTTC & 745 \\
\hline & Reverse & TCACTCTGCCTGAAGTTGTGCTCT & \\
\hline \multirow[t]{2}{*}{ rs1764345 } & Forward & GAGAAAGGGAAATAGGACTGTCCC & 463 \\
\hline & Reverse & GCTGATCTCAAAACTTCTGGCCTC & \\
\hline \multirow[t]{2}{*}{ rs1771316 } & Forward & AAGGAATCTCCATGACTCTGAAGG & 459 \\
\hline & Reverse & GTGACTTGACCATTAGTATTCCAC & \\
\hline \multirow[t]{2}{*}{ rs2039620 + rs6751 } & Forward & CTCTTCAGAATAGTCATCATGATT & 761 \\
\hline & Reverse & AGAAAAAGTACTACTGCTTATATG & \\
\hline \multirow[t]{2}{*}{ rs10799319 } & Forward & GGTTAGTCAGAATTCTAAGACGTTC & 441 \\
\hline & Reverse & ССТCAAAATAACGCTCGGAAATAAT & \\
\hline \multirow[t]{2}{*}{ rs12034829 } & Forward & GTAGCAGGAGTTACAGGCACATGC & 501 \\
\hline & Reverse & GGACCTTGGAACCCTTTAGGGCAT & \\
\hline \multirow[t]{2}{*}{ rs7555139 } & Forward & CTGGACATGTAAGTAGAGATGTTG & 441 \\
\hline & Reverse & СААСАТСТСТАСТTАСАTGTCCAG & \\
\hline \multirow[t]{2}{*}{ rs576861 } & Forward & CTTGATCCCTACCTCACACCATAG & 561 \\
\hline & Reverse & CCACAAGAGTATACAAGAGCTTGT & \\
\hline \multirow[t]{2}{*}{ rs487591 } & Forward & GAAAACTGGAAACTACTATCCTGT & 523 \\
\hline & Reverse & GAAATGCAACTTTGCAGGAGATGG & \\
\hline
\end{tabular}

teins, including the focal adhesion kinase (FAK), are phosphorylated and activate the Ras pathway. At this stage, Rho, Rac, and Cdc42, of the Rho GTPase family members, reorganize the actin cytoskeleton into distinct structures: stress fibers and focal adhesions, veil-like lamelliopodia, and filopodial microspikes (Govek et al., 2005). Then, Cdc42 binds with the insulin receptor substrate of $53 \mathrm{kDa}$ (IRSp53) and its SH3 domain with ENAH (Krugmann et al., 2001; Govek et al., 2005). Overexpression of IRSp53 in fibroblasts associated with ENAH causes filopodia formation (Krugmann et al., 2001).

ENAH has been found to be expressed in the tissues of brain, glomerular mesangial cells and interstitial cells of the kidneys in high levels (Gambaryan et al., 2001). Furthermore, the action of integrins on actin-rearrangement is known to be involved in the regulation of cellular differentiation, proliferation and survival (Kim et al., 2007), and in the leukocyte trafficking that is critical for immune surveillance and contributes to the pathogenesis of inflammatory and autoimmune diseases (Rose, 2006). Besides, ENAH is likely associated with the progression of glomerulonephritis as shown in a study on VASP (Hohenstein et al., 2005).

However, no prior study has investigated the association of ENAH polymorphisms with glomerulonephritis including $\lg A N$, especially in children. Thus, the present study was conducted to inves- tigate the association between polymorphisms of the ENAH gene and childhood IgAN.

\section{Results}

We assessed the genetic associations of ENAH SNPs in subjects with IgAN. The genotypic distributions of all SNPs in this study were consistent with Hardy-Weinberg equilibrium $(P>0.05)$. The 12 candidate SNPs (rs12034829, rs576861, rs10799319, rs487591, rs7555139, rs2039620, rs6751, rs1771316, rs4653643, rs954534, rs3795443, and rs1764345) are illustrated in Figure 1. Genotyping data from 178 childhood IgAN patients and 397 controls showed significant frequency differences in the SNPs of rs2039620, rs12034829, rs3795443 , and rs 1771316 by logistic regression of the case-control analysis with adjustment for gender. We found a significant association between rs2039620 (codominant, OR $=1.47,95 \% \mathrm{Cl}=1.01-2.13$, $P=0.039$; dominant, $\mathrm{OR}=1.53,95 \% \mathrm{Cl}=1.01$ 2.32, $P=0.041$ ), rs12034829 (codominant, OR = $1.51,95 \% \mathrm{Cl}=1.04-2.19, P=0.027$; dominant, OR $=1.59,95 \% \mathrm{Cl}=1.05-2.41, P=0.027)$, and rs379. 5443 (dominant, $\mathrm{OR}=0.59,95 \% \mathrm{Cl}=0.39-0.88, P$ $=0.011$; overdominant, $\mathrm{OR}=0.53,95 \% \mathrm{Cl}=0.35$ $0.81, P=0.003$ ) of the ENAH gene and the development of IgAN (Table 2). We calculated the sample power for the significant SNPs. In our 


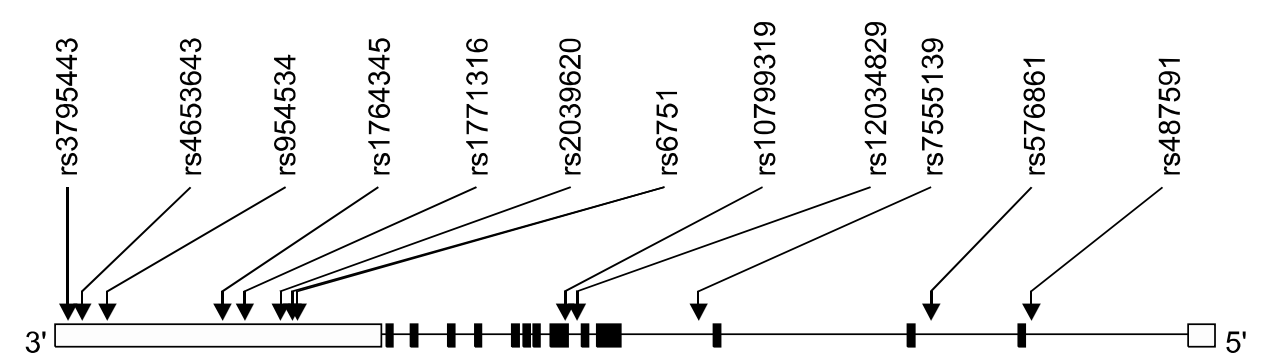

Figure 1. Gene mapping of 12 single nucleotide polymorphisms (SNPs) of the ENAH gene (chromosome 1q42.12).

case-control study, we had 0.41 and 0.65 [rs2039620; codominant, effective sample size (ESS) = 408; dominant, ESS = 225), 0.41 and 0.72 (rs12034829; codominant, ESS = 408; dominant, ESS = 196), and 0.81 and 0.89 (rs3795443; dominant, ESS = 136; overdominant, ESS = 96) power to detect a two-fold increased risk, assuming an $\alpha$-level of 0.05 . Thus, the dominant and overdominant models of rs3795443 were sufficiently powerful to determine a positive association.

Comparison of patients with the proteinuria to those without proteinuria, showed that rs12043633 was significantly different between the two groups of patients (overdominant, OR $=2.40,95 \% \mathrm{Cl}=$ 1.22-4.72, $P=0.009$ ).

With regard to the maximum proteinuria, rs3795443 (codominant, $\mathrm{OR}=0.29,95 \% \mathrm{Cl}=0.12$ $0.70, P=0.002$; dominant, $\mathrm{OR}=0.29,95 \% \mathrm{Cl}=$ $0.12-0.70, \quad P=0.003 ; \quad$ overdominant, $\quad$ R $=0.31$, $95 \% \mathrm{Cl}=0.13-0.75, P=0.005$ ), rs4653643 (codominant, $\mathrm{OR}=0.44,95 \% \mathrm{Cl}=0.23-0.83, P=0.009$; dominant, $\mathrm{OR}=0.46, \quad 95 \% \mathrm{Cl}=0.23-0.92, \quad P=$ 0.026 ), $r s 6751$ (codominant, $\mathrm{OR}=0.46,95 \% \mathrm{Cl}=$ $0.25-0.85, P=0.010$; dominant, $\mathrm{OR}=0.43,95 \% \mathrm{Cl}$ $=0.22-0.87, P=0.016$ ), rs10799319 (codominant, $\mathrm{OR}=0.45,95 \% \mathrm{Cl}=0.24-0.84, P=0.009$; dominant, $\mathrm{OR}=0.43,95 \% \mathrm{Cl}=0.21-0.85, P=0.014)$, rs7555139 (codominant, $\mathrm{OR}=0.45,95 \% \mathrm{Cl}=$ $0.24-0.84, P=0.009$; dominant, $\mathrm{OR}=0.43,95 \% \mathrm{Cl}$ $=0.21-0.85, \quad P=0.014$ ), rs576861 (codominant, $\mathrm{OR}=0.45,95 \% \mathrm{Cl}=0.24-0.83, P=0.008$; dominant, $\mathrm{OR}=0.42,95 \% \mathrm{Cl}=0.21-0.84, P=0.013)$, and rs487591 (codominant, $\mathrm{OR}=0.46,95 \% \mathrm{Cl}=$ $0.25-0.85, P=0.009$; dominant, $\mathrm{OR}=0.43,95 \% \mathrm{Cl}$ $=0.21-0.86, P=0.015)$ showed statistically significant allele frequency differences (Table 3).

Comparison of patients with and without hematuria showed that rs4653643 (recessive, OR = $0.21,95 \% \mathrm{Cl}=0.05-0.87, P=0.040$ ), rs6751 (recessive, $\mathrm{OR}=0.19,95 \% \mathrm{Cl}=0.05-0.69, P=0.016)$, rs10799319 (recessive, OR $=0.19,95 \% \mathrm{Cl}=0.05-$ $0.69, P=0.016$ ), rs7555139 (recessive, $O R=0.19$, $95 \% \mathrm{Cl}=0.05-0.69, P=0.016$ ), rs576861 (recessive, $O R=0.19,95 \% \mathrm{Cl}=0.05-0.68, P=0.015)$, and rs487591 (recessive, OR $=0.18,95 \% \mathrm{Cl}=$ $0.05-0.66, P=0.013$ ) had significant allele frequ- ency differences (data not shown). Of note is that all the SNPs associated with the presence of gross hematuria, as a first symptom of $\lg \mathrm{AN}$, were also associated with the development of maximum proteinuria $>4 \mathrm{mg} / \mathrm{m}^{2} / \mathrm{h}$.

In terms of associations between the SNPs and the presence of pathologically advanced disease markers, of the 12 SNPs, rs3795443 (codominant, $\mathrm{OR}=0.36,95 \% \mathrm{Cl}=0.14-0.92, P=0.034$; dominant, $\mathrm{OR}=0.34,95 \% \mathrm{Cl}=0.11-0.99, \quad P=0.048$ ) was found to be associated with progression of pathological findings. Notably, rs3795443 was also a significant SNP associated with the presence of $\lg \mathrm{AN}$, in the patient-control study of maximum proteinuria. However, no significant association was found with the presence of podocyte effacement (data not shown).

As shown in Figure 2, in the measurement of pair-wise linkage disequilibrium (LD), one LD block was identified by the Gabriel method (Gabriel, Schaffner et al., 2002). This LD block showed statistically significant overall haplotype association with disease using Haploview (GATACTCAAGCA) (Table 4).

\section{Discussion}

All three Ena/VASP family members (ENAH, VASP, and $E v l$ ) have been studied with regard to neuronal migrations and cortical development of brain regulating growth cone dynamics and axon guidance (Gambaryan et al., 2001; Vanderzalm and Garriga, 2007). VASP plays an important role in the following: the inhibition of platelet function, fibrinogen binding, increase of vascular permeability for the control of cytoskeletal tension at the endothelial cell to cell junction, promotion of polymorpholeukocytes migration across the vascular endothelium, as well as in repairing respiratory epithelial tissue of asthmatic patients (Gambaryan et al., 2001; Comerford et al., 2002; Hastie et al., 2006).

Moreover, a study on the association of VASP with nephritis was reported by Hohenstein et al. (2005) who showed that VASP deficient mice were protected from long-term progression of nephro- 
Table 2. Logistic regression analysis of ENAH polymorphisms in control and IgAN patients with adjustment for gender ${ }^{a}$.

\begin{tabular}{|c|c|c|c|c|c|c|}
\hline \multirow{2}{*}{ SNP } & \multirow{2}{*}{ Genotype } & $\operatorname{IgAN}$ & Control & \multirow{2}{*}{ Models } & \multirow{2}{*}{ OR (95\% Cl) } & \multirow{2}{*}{$P$-value } \\
\hline & & $n(\%)$ & $n(\%)$ & & & \\
\hline rs12034829 & $\mathrm{A} / \mathrm{A}$ & $137(77.8)$ & $271(68.8)$ & Codominant & $1.51(1.04-2.19)$ & 0.027 \\
\hline \multirow[t]{3}{*}{ intron } & $A / C$ & $36(20.4)$ & $112(28.4)$ & Dominant & $1.59(1.05-2.41)$ & 0.027 \\
\hline & $\mathrm{C} / \mathrm{C}$ & $3(1.7)$ & $11(2.8)$ & Recessive & $1.69(0.46-6.16)$ & 0.410 \\
\hline & & & & Overdominant & $1.53(1.00-2.36)$ & 0.046 \\
\hline rs576861 & $T / T$ & $87(48.9)$ & $200(51.7)$ & Codominant & $1.00(0.75-1.32)$ & 0.980 \\
\hline \multirow[t]{3}{*}{ intron } & $\mathrm{T} / \mathrm{C}$ & $80(44.9)$ & $154(39.8)$ & Dominant & $0.90(0.63-1.29)$ & 0.570 \\
\hline & $\mathrm{C} / \mathrm{C}$ & $11(6.2)$ & 33 (8.5) & Recessive & $1.44(0.71-2.93)$ & 0.300 \\
\hline & & & & Overdominant & $0.81(0.57-1.17)$ & 0.260 \\
\hline rs10799319 & $\mathrm{G} / \mathrm{G}$ & 87 (49.1) & $200(51.4)$ & Codominant & $1.00(0.75-1.33)$ & 0.990 \\
\hline \multirow[t]{3}{*}{ intron } & $A / G$ & $79(44.6)$ & $157(40.4)$ & Dominant & $0.92(0.64-1.31)$ & 0.640 \\
\hline & $\mathrm{A} / \mathrm{A}$ & $11(6.2)$ & 32 (8.2) & Recessive & $1.37(0.67-2.80)$ & 0.380 \\
\hline & & & & Overdominant & $0.84(0.59-1.21)$ & 0.350 \\
\hline rs487591 & $\mathrm{G} / \mathrm{G}$ & $91(50.6)$ & $245(51.9)$ & Codominant & $1.01(0.77-1.33)$ & 0.930 \\
\hline \multirow[t]{3}{*}{ intron } & $A / G$ & 78 (43.3) & $189(40)$ & Dominant & $0.94(0.66-1.32)$ & 0.710 \\
\hline & $\mathrm{A} / \mathrm{A}$ & $11(6.1)$ & $38(8.1)$ & Recessive & $1.39(0.69-2.79)$ & 0.350 \\
\hline & & & & Overdominant & $1.39(0.69-2.79)$ & 0.350 \\
\hline rs7555139 & $\mathrm{A} / \mathrm{A}$ & 87 (49.1) & $200(51.0)$ & Codominant & $1.01(0.76-1.34)$ & 0.960 \\
\hline \multirow[t]{3}{*}{ intron } & $A / G$ & $79(44.6)$ & $160(40.8)$ & Dominant & $0.93(0.65-1.33)$ & 0.700 \\
\hline & $\mathrm{G} / \mathrm{G}$ & $11(6.2)$ & 32 (8.2) & Recessive & $1.36(0.66-2.77)$ & 0.390 \\
\hline & & & & Overdominant & $0.86(0.60-1.23)$ & 0.960 \\
\hline rs2039620 & $T / T$ & $137(77.4)$ & $267(69.0)$ & Codominant & $1.47(1.01-2.13)$ & 0.039 \\
\hline \multirow[t]{3}{*}{ exon } & $\mathrm{T} / \mathrm{C}$ & 37 (20.4) & $133(28.1)$ & Dominant & $1.53(1.01-2.32)$ & 0.041 \\
\hline & $\mathrm{C} / \mathrm{C}$ & $3(1.7)$ & $12(2.5)$ & Recessive & $1.73(0.47-6.32)$ & 0.390 \\
\hline & & & & Overdominant & $1.47(0.96-2.26)$ & 0.071 \\
\hline rs6751 & $\mathrm{T} / \mathrm{T}$ & 87 (49.4) & $199(50.6)$ & Codominant & $1.03(0.78-1.37)$ & 0.820 \\
\hline \multirow[t]{3}{*}{ exon } & $\mathrm{T} / \mathrm{C}$ & 78 (43.3) & $161(41.0)$ & Dominant & $0.96(0.67-1.38)$ & 0.830 \\
\hline & $\mathrm{C} / \mathrm{C}$ & $11(6.1)$ & $33(8.4)$ & Recessive & $1.40(0.69-2.84)$ & 0.350 \\
\hline & & & & Overdominant & $0.88(0.61-1.26)$ & 0.470 \\
\hline rs1771316 & $\mathrm{C} / \mathrm{C}$ & $156(88.1)$ & $327(82.6)$ & Codominant & $1.63(0.99-2.69)$ & 0.044 \\
\hline \multirow[t]{3}{*}{ exon } & $\mathrm{A} / \mathrm{C}$ & $21(11.9)$ & 63 (15.9) & Dominant & $1.58(0.93-2.67)$ & 0.082 \\
\hline & $\mathrm{A} / \mathrm{A}$ & $0(0)$ & $6(1.5)$ & Recessive & $\mathrm{NA}(0.00-\mathrm{NA})$ & 0.040 \\
\hline & & & & Overdominant & $1.42(0.83-2.42)$ & 0.190 \\
\hline rs4653643 & $\mathrm{G} / \mathrm{G}$ & $89(50.6)$ & $210(53.4)$ & Codominant & $0.98(0.74-1.32)$ & 0.920 \\
\hline \multirow[t]{3}{*}{ exon } & $\mathrm{A} / \mathrm{G}$ & 78 (44.3) & $155(39.4)$ & Dominant & $0.90(0.63-1.29)$ & 0.570 \\
\hline & $\mathrm{A} / \mathrm{A}$ & $9(5.1)$ & $28(7.1)$ & Recessive & $1.42(0.65-3.08)$ & 0.370 \\
\hline & & & & Overdominant & $0.83(0.58-1.19)$ & 0.310 \\
\hline rs954534 & $T / T$ & $157(88.7)$ & $336(85.9)$ & Codominant & $1.27(0.71-2.07)$ & 0.470 \\
\hline \multirow[t]{3}{*}{ exon } & $\mathrm{T} / \mathrm{C}$ & 19 (10.7) & 55 (14.1) & Dominant & $1.29(0.74-2.23)$ & 0.360 \\
\hline & $\mathrm{C} / \mathrm{C}$ & $1(0.6)$ & $0(0)$ & Recessive & 0.00 (0.00-NA) & 0.160 \\
\hline & & & & Overdominant & $1.36(0.78-2.37)$ & 0.270 \\
\hline rs3795443 & $\mathrm{A} / \mathrm{A}$ & $121(68.8)$ & $313(79.0)$ & Codominant & $0.70(0.49-1.00)$ & 0.052 \\
\hline \multirow[t]{3}{*}{ exon } & $\mathrm{A} / \mathrm{G}$ & $53(30.1)$ & 73 (18.4) & Dominant & $0.59(0.39-0.88)$ & 0.011 \\
\hline & $\mathrm{G} / \mathrm{G}$ & $2(1.1)$ & $10(2.5)$ & Recessive & $2.20(0.47-10.23)$ & 0.280 \\
\hline & & & & Overdominant & $0.53(0.35-0.81)$ & 0.003 \\
\hline rs1764345 & $\mathrm{A} / \mathrm{A}$ & $157(88.7)$ & 337 (86.2) & Codominant & $1.19(0.70-2.03)$ & 0.510 \\
\hline \multirow[t]{3}{*}{ exon } & A/G & $19(10.7)$ & $54(13.8)$ & Dominant & $1.26(0.73-2.19)$ & 0.400 \\
\hline & $\mathrm{G} / \mathrm{G}$ & $1(0.6)$ & $0(0)$ & Recessive & $0.00(0.00-N A)$ & 0.160 \\
\hline & & & & Overdominant & $1.33(0.76-2.33)$ & 0.300 \\
\hline
\end{tabular}

${ }^{a}$ Twelve single nucleotide polymorphisms (SNPs) of ENAH are shown, which were genotyped from ENAH in 178 patients with IgAN from the Kyung Hee medical center, Seoul, Korea and 397 control subjects; rs2039620, rs12034829, rs3795443 and rs1771316 showed statistically significant differences. Genotype distributions are shown as the number (\%), odds ratio (OR), 95\% confidence interval $(\mathrm{Cl})$, and $P$ values were determined by logistic regression analysis with codominant, dominant, and recessive models controlling for gender as covariates. The total number of each SNP is different, because genotypes of some SNPs were unreadable. 
Table 3. Logistic regression analysis of ENAH polymorphisms in patients with $\operatorname{lgA}$ nephropathy and maximum proteinuria $\left(>4 \mathrm{mg} / \mathrm{m}^{2} / \mathrm{h}\right.$ or $\leq 4 \mathrm{mg} / \mathrm{m}^{2} / \mathrm{h}$ ) after adjustment for gender and age ${ }^{\mathrm{a}}$.

\begin{tabular}{|c|c|c|c|c|c|c|}
\hline SNP & Genotype & $\begin{array}{c}>4 \mathrm{mg} / \mathrm{m}^{2} / \mathrm{h} \\
n(\%)\end{array}$ & $\frac{\leq 4 \mathrm{mg} / \mathrm{m}^{2} / \mathrm{h}}{n(\%)}$ & Models & OR (95\% Cl) & $P$-value \\
\hline rs12034829 & $\mathrm{A} / \mathrm{A}$ & $96(76.8)$ & $39(79.6)$ & Codominant & $0.93(0.45-1.92)$ & 0.850 \\
\hline \multirow[t]{3}{*}{ intron } & $\mathrm{A} / \mathrm{C}$ & $27(21.6)$ & 9 (18.4) & Dominant & $0.91(0.40-2.07)$ & 0.820 \\
\hline & $\mathrm{C} / \mathrm{C}$ & $2(1.6)$ & $1(2)$ & Recessive & $1.02(0.09-11.83)$ & 0.990 \\
\hline & & & & Overdominant & $0.90(0.38-2.12)$ & 0.810 \\
\hline rs576861 & $\mathrm{T} / \mathrm{T}$ & $54(42.5)$ & 32 (65.3) & Codominant & $0.45(0.24-0.83)$ & 0.008 \\
\hline \multirow[t]{3}{*}{ intron } & $\mathrm{T} / \mathrm{C}$ & $63(49.6)$ & $16(32.6)$ & Dominant & $0.42(0.21-0.84)$ & 0.013 \\
\hline & $\mathrm{C} / \mathrm{C}$ & $10(7.9)$ & $1(2)$ & Recessive & $0.26(0.03-2.13)$ & 0.140 \\
\hline & & & & Overdominant & $0.52(0.26-1.05)$ & 0.062 \\
\hline rs10799319 & $\mathrm{G} / \mathrm{G}$ & $54(42.9)$ & 32 (65.3) & Codominant & $0.45(0.24-0.84)$ & 0.009 \\
\hline \multirow{3}{*}{ intron } & $\mathrm{A} / \mathrm{G}$ & $62(49.2)$ & $16(32.6)$ & Dominant & $0.43(0.21-0.85)$ & 0.014 \\
\hline & $\mathrm{A} / \mathrm{A}$ & $10(7.9)$ & $1(2)$ & Recessive & $0.26(0.03-2.11)$ & 0.140 \\
\hline & & & & Overdominant & $0.53(0.26-1.06)$ & 0.070 \\
\hline rs487591 & $\mathrm{G} / \mathrm{G}$ & $54(43.2)$ & $32(65.3)$ & Codominant & $0.46(0.25-0.85)$ & 0.009 \\
\hline \multirow[t]{3}{*}{ intron } & $A / G$ & $61(48.8)$ & $16(32.6)$ & Dominant & $0.43(0.21-0.86)$ & 0.015 \\
\hline & $\mathrm{A} / \mathrm{A}$ & $10(8)$ & $1(2)$ & Recessive & $0.26(0.03-2.10)$ & 0.140 \\
\hline & & & & Overdominant & $0.53(0.27-1.07)$ & 0.074 \\
\hline rs7555139 & $\mathrm{A} / \mathrm{A}$ & $54(42.9)$ & 32 (65.3) & Codominant & $0.45(0.24-0.84)$ & 0.009 \\
\hline \multirow[t]{3}{*}{ intron } & $\mathrm{A} / \mathrm{G}$ & $62(49.2)$ & $16(32.6)$ & Dominant & $0.43(0.21-0.85)$ & 0.014 \\
\hline & $\mathrm{G} / \mathrm{G}$ & $10(7.9)$ & $1(2)$ & Recessive & $0.26(0.03-2.11)$ & 0.140 \\
\hline & & & & Overdominant & $0.53(0.26-1.06)$ & 0.070 \\
\hline rs2039620 & $\mathrm{T} / \mathrm{T}$ & $96(76.2)$ & 39 (79.6) & Codominant & $0.92(0.45-1.89)$ & 0.810 \\
\hline \multirow[t]{3}{*}{ exon } & $\mathrm{T} / \mathrm{C}$ & $28(22.2)$ & $9(18.4)$ & Dominant & $0.89(0.39-2.02)$ & 0.780 \\
\hline & $\mathrm{C} / \mathrm{C}$ & $2(1.6)$ & $1(2)$ & Recessive & $1.02(0.09-11.80)$ & 0.990 \\
\hline & & & & Overdominant & $0.88(0.38-2.07)$ & 0.770 \\
\hline rs6751 & $\mathrm{T} / \mathrm{T}$ & $54(43.2)$ & $32(65.3)$ & Codominant & $0.46(0.25-0.85)$ & 0.010 \\
\hline \multirow[t]{3}{*}{ exon } & $\mathrm{T} / \mathrm{C}$ & $61(48.8)$ & $16(32.6)$ & Dominant & $0.43(0.22-0.87)$ & 0.016 \\
\hline & $\mathrm{C} / \mathrm{C}$ & $10(8)$ & $1(2)$ & Recessive & $0.26(0.03-2.08)$ & 0.130 \\
\hline & & & & Overdominant & $0.54(0.27-1.09)$ & 0.079 \\
\hline rs4653643 & $\mathrm{G} / \mathrm{G}$ & $56(44.8)$ & 32 (65.3) & Codominant & $0.44(0.23-0.83)$ & 0.009 \\
\hline \multirow[t]{3}{*}{ exon } & $\mathrm{A} / \mathrm{G}$ & $60(48)$ & 17 (34.7) & Dominant & $0.46(0.23-0.92)$ & 0.026 \\
\hline & $\mathrm{A} / \mathrm{A}$ & $9(7.2)$ & $0(0)$ & Recessive & $0.00(0.00-\mathrm{NA})$ & 0.019 \\
\hline & & & & Overdominant & $0.60(0.30-1.20)$ & 0.150 \\
\hline rs954534 & $\mathrm{T} / \mathrm{T}$ & 112 (88.9) & $43(87.8)$ & Codominant & $0.96(0.37-2.54)$ & 0.940 \\
\hline \multirow[t]{3}{*}{ exon } & $\mathrm{T} / \mathrm{C}$ & $13(10.3)$ & $6(12.2)$ & Dominant & $1.04(0.37-2.92)$ & 0.940 \\
\hline & $\mathrm{C} / \mathrm{C}$ & $1(0.8)$ & $0(0)$ & Recessive & $0.00(0.00-N A)$ & 0.400 \\
\hline & & & & Overdominant & $1.14(0.40-3.22)$ & 0.810 \\
\hline rs3795443 & $\mathrm{A} / \mathrm{A}$ & $78(62.4)$ & $42(85.7)$ & Codominant & $0.29(0.12-0.70)$ & 0.002 \\
\hline \multirow[t]{3}{*}{ exon } & $\mathrm{A} / \mathrm{G}$ & $45(36)$ & 7 (14.3) & Dominant & $0.29(0.12-0.70)$ & 0.003 \\
\hline & $\mathrm{G} / \mathrm{G}$ & $2(1.6)$ & $0(0)$ & Recessive & $0.00(0.00-\mathrm{NA})$ & 0.290 \\
\hline & & & & Overdominant & $0.31(0.13-0.75)$ & 0.005 \\
\hline rs1764345 & $\mathrm{A} / \mathrm{A}$ & 112 (88.9) & $43(87.8)$ & Codominant & $0.96(0.37-2.54)$ & 0.940 \\
\hline \multirow[t]{3}{*}{ exon } & $\mathrm{A} / \mathrm{G}$ & $13(10.3)$ & $6(12.2)$ & Dominant & $1.04(0.37-2.92)$ & 0.940 \\
\hline & $\mathrm{G} / \mathrm{G}$ & $1(0.8)$ & $0(0)$ & Recessive & $0.00(0.00-\mathrm{NA})$ & 0.400 \\
\hline & & & & Overdominant & $1.14(0.40-3.22)$ & 0.810 \\
\hline
\end{tabular}

${ }^{a}$ Twelve single nucleotide polymorphisms (SNPs) of ENAH were genotyped in 176 IgAN patients. The total numbers of SNPs differ, because genotypes of some SNPs were not determined; rs1771316 was excluded from the analysis, because of its low minor allele frequency. Here, maximum proteinuria means the largest amount of proteinuria recorded at any time during the course of disease.

toxic nephritis by renal endothelial cell and podocyte preservation and reduced apoptotic activity of peritubular endothelial cells.

In addition, ENAH has been shown to be associated with carcinogenesis, tumor progression and metastasis (Di Modugno et al., 2004, 2006, 2007). Moreover, it has been correlated with the potentiation of EGF-induced membrane protrusion and increase in the matrix degradation activity of tumor cells (Philippar et al., 2008). 


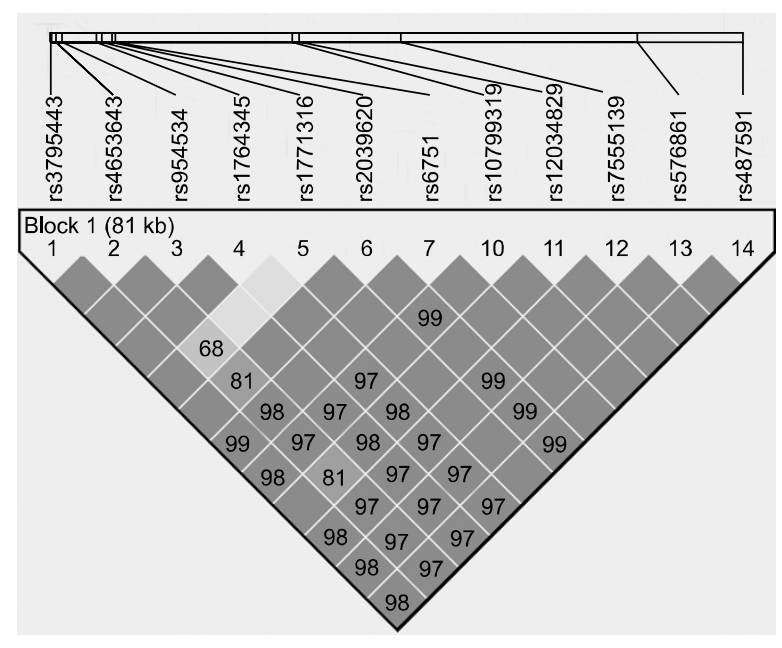

Figure 2. Haplotype block organization of the ENAH gene ${ }^{a}$. ${ }^{a}$ Each box represents linkage disequilibrium (LD) (range 0-1) between pairs of single-nucleotide polymorphism (SNP) markers as generated with the Haploview program. Red shading indicates strong LD (no number means a score 1). Purple shading indicates uninformative results and white shading indicates strong evidence for recombination.

In the present study, we demonstrated an association between SNPs and/or haplotypes of ENAH and the development and progression of disease and the development of proteinuria and hematuria in IgAN patients. Prior studies have reported an association between ENAH and nephritis.

First, in a rat study, the renal tissues showed abundant ENAH and VASP expression (Gambaryan et al., 2001), and the mesangial cells had intense signals for both ENAH and VASP with light staining in the glomerular endothelial cells and podocytes. Blood vessel walls and interstitial cells, outlining the outer circumference of the convoluted tubules, in the loop of Henle, and collecting ducts also demonstrated strong expression levels. Because all of the structures are associated with the regulation of renal blood flow, glomerular filtration rate, and urinary concentrating mechanisms, several kidney diseases including IgAN could be associated with the coding genes of VASP and

\section{ENAH.}

Second, some studies have suggested a possible role of ENAH in the development of proteinuria, an important feature in the progression of nephritis. Proteinuria is produced by effacement changes of the podocyte foot process in the glomerulus. $\mathrm{Cu}$ rrent thinking suggests that the onset of podocyte foot process effacement is a migratory event; this suggests that rearrangement of the podocyte actin cytoskeleton into a migratory phenotype results in abnormal coordination of this network (Oh et al., 2004; Reiser et al., 2004; Yanagida-Asanuma et al., 2007).

In a recent study, synaptopodin, an actin-associated protein essential for the integrity of the podocyte actin skeleton was shown to have a protective role against proteinuria by direct binding to IRSp53 and suppression of Cdc42:IRSp53:ENAH signaling, which eventually stabilized glomerular filtration by shifting the plasticity of the podocyte actin skeleton from a motile to a contractile phenotype (Yanagida-Asanuma et al., 2007). Furthermore, the expression of synaptopodin was weak or absent in advanced glomerulonephropathy, and this phenomenon was thought to precede changes in the podocyte phenotype (Kemeny et al., 1997; Barisoni et al., 1999; Srivastava et al., 2001; Oh et al., 2004).

However, we did not observe a correlation between ENAH SNPS and the presence of foot process effacement in comparison with the presence of proteinuria and maximum proteinuria. This might be explained by the fact that most of the patients in the present study were diagnosed during the early disease stage, and thus, the pathological changes may not have been fully expressed, as reflected by relatively mild kidney biopsy results. In addition, the limitations of renal biopsy sampling might also explain this finding; the biopsy might be performed at an unaffected site. However, most centers routinely perform ultrasound-guided renal biopsy for confirmative investigation for many forms of renal parenchymal

Table 4. Analysis of haplotypes of a LD block in patients with $\operatorname{lgA}$ nephropathy and control subjects ${ }^{\mathrm{a}}$.

\begin{tabular}{|c|c|c|c|c|c|c|}
\hline \multirow{2}{*}{ Haplotype } & \multicolumn{2}{|c|}{ Ratio Counts } & \multicolumn{2}{|c|}{ Frequencies } & \multirow{2}{*}{ Chi Square } & \multirow{2}{*}{$P$ value } \\
\hline & Case & Control & Case & Control & & \\
\hline AGTACTTGAATG & $260.0: 101.0$ & $672.0: 268.0$ & 0.720 & 0.715 & 0.037 & 0.848 \\
\hline GATACTCAAGCA & 58.0:303.0 & 109.0:831.0 & 0.161 & 0.116 & 4.657 & 0.031 \\
\hline AACGCCCACGCA & $21.0: 340.0$ & $70.0: 870.0$ & 0.058 & 0.074 & 1.065 & 0.302 \\
\hline AATAACCACGCA & $18.0: 343.0$ & $64.0: 876.0$ & 0.050 & 0.068 & 1.466 & 0.226 \\
\hline AGTAACCACGCA & $4.0: 357.0$ & 21.0:919.0 & 0.011 & 0.022 & 1.754 & 0.185 \\
\hline
\end{tabular}

aLD block consists of 12 SNPs: rs3795443, rs4653643, rs954534, rs1764345, rs1771316, rs2039620, rs6751, rs10799319, rs12034829, rs7555139, rs576861, and rs487591. LD, linkage disequilibrium. 
diseases (Madaio, 1990; Tang and Lai, 2004). Especially for chronic nephritic diseases, the pathologic findings of renal cortex composed with vessels and glomerulus are more important than those of medulla. Even though we exam only small parts of renal tissue, generally they include more than 12 glomeruli and in most medical centers it is recognized as a method to represent glomeruli changes of the whole kidney.

Another limitation of this study was that we could not enroll age matched controls. However, IgAN is known to develop in the third decade of life; healthy controls should be more than $20 \mathrm{yr}$ of age to avoid individuals with undetected or sub-clinical $\operatorname{lgAN}$. Thus, in pediatric research on IgAN, the presence of a substantial age gaps between cases and controls appears to be unavoidable, which is why we were unable to adjust for age in the case/control analysis. Other investigators have used adult controls in studies on SNPs in childhood IgAN (Maruyama et al., 2001; Nakanishi et al., 2004).

There is only one published study on the SNPs of $E N A H$. It was performed to identify susceptibility genes for schizophrenia and involved several genes known to be responsible for neuronal migration that include ENAH in the Norwegian, Swedish, and Danish population (Kahler et al., 2008). Even though there were no significant single association markers identified, genetic association was found as a haplotype block with 12 markers and several haplotype alleles that had significant variations (most significant combination, rs1075364-rs10915846). Therefore, SNPs of ENAH might provide novel markers associated with the development of diseases that involve actin rearrangement including cellular migration and structural changes.

In summary, based on our case-controlled study of polymorphisms of the ENAH gene and genotyping of patients with IgAN and control subjects, we observed significant associations of ENAH SNPs with the development of IgAN. There were associations with pathologically confirmed progression of disease, the presence of gross hematuria, as the first symptom of IgAN, the presence of proteinuria at the time of renal biopsy, and the presence of maximum proteinuria during the course of $\lg \mathrm{AN}$, in a patient subgroup analysis.

\section{Methods}

\section{Subjects}

We examined 176 Korean pediatric patients with biopsy proven IgAN [99 boys, $11.62 \pm 3.94 \mathrm{yr}$ (mean age $\pm \mathrm{SD}$ );
77 girls, $11.59 \pm 3.97 \mathrm{yr}]$ and 397 healthy controls (175 males, $38.80 \pm 9.52$ yr; 222 females, $40.39 \pm 9.21 \mathrm{yr}$ ). All patients had relatively early disease; they were referred to our center due to abnormal results on a school screening urinalysis. All patients with unexplained hematuria, prolonged, and/or concomitant proteinuria underwent kidney biopsy. Healthy controls were also recruited based on routine screening findings. Screening included the completion of a questionnaire that addressed the presence of symptoms and medical history, in addition to blood pressure, electrocardiography, abdominal sonography, and laboratory test findings, such as, complete blood count, fasting glucose level, total cholesterol, triglyceride, HDL-cholesterol, rheumatoid factor, hepatitis $B$ and $C$ viral markers, hemoglobin A1C, liver enzymes, blood urea nitrogen, creatinine, electrolytes, and urinalysis findings (protein, glucose, and occult blood). Controls with an abnormal result for any item were excluded.

The IgAN patients were divided into two subgroups according to the presence of proteinuria [proteinuria $\leq$ or $4 \mathrm{mg} / \mathrm{m}^{2} / \mathrm{h}$; proteinuria group $(n=70, \mathrm{M}: \mathrm{F}=47: 23 ; 11.59$ $\pm 3.95)$ and no proteinuria group $(n=106, \mathrm{M}: \mathrm{F}=52: 54$; $11.62 \pm 3.95)$. To include late symptoms of disease, the largest amount of proteinuria, anytime during the course of IgAN, was analyzed [maximum proteinuria $>4$ or $\leq 4$ $\mathrm{mg} / \mathrm{m}^{2} / \mathrm{h}, n=127(\mathrm{M}: \mathrm{F}=82: 45 ; 11.59 \pm 3.95)$ and $49(\mathrm{M}: \mathrm{F}$ $=17: 32 ; 11.67 \pm 3.96)$, respectively]. In addition, patients with and without gross hematuria were evaluated by the presentation of gross hematuria as the first symptom of IgAN [gross: hematuria $(+), n=28(\mathrm{M}: \mathrm{F}=16: 12 ; 11.57 \pm$ 3.99); gross hematuria (-), 148 (M:F=83:65; $11.59 \pm$ 3.95), respectively]. Moreover, the patients were subgrouped into an effacement group $(n=75, \mathrm{M}: \mathrm{F}=48: 27$; $11.55 \pm 3.96)$ and non-effacement group $(n=101, \mathrm{M}: \mathrm{F}=$ $51: 50 ; 11.58 \pm 3.96$ ) according to the presence of podocyte foot process effacement based on electron microscopic findings. The association of ENAH SNPs with the pathological progression of IgAN was assessed by patient subgrouping according to disease stage based on pathological markers obtained from the kidney biopsy, such as, interstitial fibrosis, tubular atrophy, or global sclerosis [early group $(n=159, \mathrm{M}: \mathrm{F}=84: 75 ; 11.55 \pm 3.96)$, and advanced group $(n=17, \mathrm{M}: \mathrm{F}=15: 2 ; 11.65 \pm 4.00)]$.

This study was approved by the ethics review committee of the Medical Research Institute, Kyung Hee University Medical Center, Seoul, Korea. Written informed consent was obtained from all subjects.

\section{SNP selection and genotyping}

A total of 12 SNPs (single nucleotide polymorphisms) of the ENAH gene were selected on the basis of extensive database searches (http://www.ebi.ac.uk/ensemble/, http:// ncbi.nlm.nih.gov/SNP) for this study, based on heterozygosity (above 0.1 ) and a minor allele frequency (MAF) above 0.05. Twelve SNPs of ENAH were selected; five intron regions (rs12034829, rs576861, rs10799319, rs487591, rs7555139) and seven exons (rs2039620, rs6751, rs1771316, rs4653643, rs954534, rs3795443, rs1764345).

DNA was isolated from a peripheral blood sample using the Core One Blood Genomic DNA Isolation Kit (CoreBioSystem, Seoul, Korea). The SNP genotyping was performed by direct sequencing. Genomic DNA was amplified 
using the following primers for each SNP of the ENAH gene (Table 1). The samples were sequenced using an ABI Prism 377 automatic sequencer (PE Applied Biosystems, Foster City, CA). Sequence data were analyzed using SeqManll software (DNASTAR Inc., Madison, WI).

\section{Statistical analysis}

We analyzed 12 SNPs of ENAH (rs12034829, rs576861, rs10799319, rs487591, rs7555139, rs2039620, rs6751, rs1771316, rs4653643, rs954534, rs3795443, and rs1764345 ) in 178 patients with childhood IgAN and 397 controls. To study the association of the SNPs with disease progression, the 12 SNPs in the early disease group were compared to the same 12 SNPs in the advanced disease group.

For the case-control association study, Hardy-Weinberg equilibrium (HWE) for all SNPs was assessed using SNPstats in both the cases and controls. A linkage disequilibrium (LD) block of polymorphisms was tested using Haploview (version 4.1). To calculate odds ratios, 95\% confidence intervals $(\mathrm{Cls})$, and $P$ values for the association study between SNPs and the development of IgAN and correlations between SNPs and IgAN subgroups we used SNPstats, HapAnalyzer version 1.0 and SNP. analyzer (ISTECH Inc., Goyang, Korea). For comparisons between IgAN patients and healthy controls, we adjusted for gender only, for the comparisons between IgAN subgroups gender and age were controlled. The calculations for power and sample size used the standard approximation to the binomial distribution. To avoid static error, a permutation test was performed (http://stat.ubc.ca/ rollin/ stats/ssize/b1.html) (Rosner, 1995). To reduce experimental error, the effective sample size was adjusted (calculated sample size $\times 100 / 95$ ). We calculated the sample power required for significant SNPs to confirm the effects.

\section{Acknowledgements}

This Research was supported by the Program of Kyung Hee University for the Young Researcher of Medical Science in 2009 (KHU-20091402).

\section{References}

Barisoni L, Kriz W, Mundel P, D'Agati V. The dysregulated podocyte phenotype: a novel concept in the pathogenesis of collapsing idiopathic focal segmental glomerulosclerosis and HIV-associated nephropathy. J Am Soc Nephrol 1999; 10:51-61

Bear JE, Loureiro JJ, Libova I, Fassler R, Wehland J, Gertler FB. Negative regulation of fibroblast motility by Ena/VASP proteins. Cell 2000;101:717-28

Boeda B, Briggs DC, Higgins T, Garvalov BK, Fadden AJ, McDonald NQ, Way M. Tes, a specific Mena interacting partner, breaks the rules for EVH1 binding. Mol Cell 2007;28:1071-82

Comerford KM, Lawrence DW, Synnestvedt K, Levi BP, Colgan SP. Role of vasodilator-stimulated phosphoprotein in
PKA-induced changes in endothelial junctional permeability. FASEB J 2002;16:583-5

Di Modugno F, Bronzi G, Scanlan MJ, Del Bello D, Cascioli S, Venturo I, Botti C, Nicotra MR, Mottolese M, Natali PG, Santoni A, Jager E, Nistico P. Human Mena protein, a serex-defined antigen overexpressed in breast cancer eliciting both humoral and CD8+ T-cell immune response. Int J Cancer 2004;109:909-18

Di Modugno F, DeMonte L, Balsamo M, Bronzi G, Nicotra MR, Alessio M, Jager E, Condeelis JS, Santoni A, Natali PG, Nistico P. Molecular cloning of hMena (ENAH) and its splice variant $h M e n a+11 a$ : epidermal growth factor increases their expression and stimulates hMena+11a phosphorylation in breast cancer cell lines. Cancer Res 2007;67:2657-65

Di Modugno F, Mottolese M, Di Benedetto A, Conidi A, Novelli F, Perracchio L, Venturo I, Botti C, Jager E, Santoni A, Natali PG, Nistico P. The cytoskeleton regulatory protein hMena (ENAH) is overexpressed in human benign breast lesions with high risk of transformation and human epidermal growth factor receptor-2-positive/hormonal receptor-negative tumors. Clin Cancer Res 2006;12:1470-8

Gabriel SB, Schaffner SF, Nguyen H, Moore JM, Roy J, Blumenstiel B, Higgins J, DeFelice M, Lochner A, Faggart M, Liu-Cordero SN, Rotimi C, Adeyemo A, Cooper R, Ward R, Lander ES, Daly MJ, Altshuler D. The structure of haplotype blocks in the human genome. Science 2002; 296:2225-9

Gambaryan S, Hauser W, Kobsar A, Glazova M, Walter U. Distribution, cellular localization, and postnatal development of VASP and Mena expression in mouse tissues. Histochem Cell Biol 2001;116:535-43

Govek EE, Newey SE, Van Aelst L. The role of the Rho GTPases in neuronal development. Genes Dev 2005;19: 1-49

Hastie AT, Wu M, Foster GC, Hawkins GA, Batra V, Rybinski KA, Cirelli R, Zangrilli JG, Peters SP. Alterations in vasodilator-stimulated phosphoprotein (VASP) phosphorylation: associations with asthmatic phenotype, airway inflammation and beta2-agonist use. Respir Res 2006;7:25

Hohenstein B, Kasperek L, Kobelt DJ, Daniel C, Gambaryan S, Renne T, Walter U, Amann KU, Hugo CP. Vasodilatorstimulated phosphoprotein-deficient mice demonstrate increased platelet activation but improved renal endothelial preservation and regeneration in passive nephrotoxic nephritis. J Am Soc Nephrol 2005;16:986-96

Kahler AK, Djurovic S, Kulle B, Jonsson EG, Agartz I, Hall H, Opjordsmoen S, Jakobsen KD, Hansen T, Melle I, Werge T, Steen VM, Andreassen OA. Association analysis of schizophrenia on 18 genes involved in neuronal migration: MDGA1 as a new susceptibility gene. Am J Med Genet B Neuropsychiatr Genet 2008;147B:1089-100

Kemeny E, Durmuller U, Nickeleit V, Gudat F, Mihatsch MJ. Distribution of podocyte protein (44 KD) in different types of glomerular diseases. Virchows Arch 1997;431:425-30

Kim SM, Kim N, Lee S, Kim do K, Lee YM, Ahn SH, Song JH, Choi BK, Wu C, Jung KY. TGF-beta1-induced PINCH-1ILK-alpha-parvin complex formation regulates mesangial cell proliferation and hypertrophy. Exp Mol Med 2007;39: 
$514-23$

Krause M, Dent EW, Bear JE, Loureiro JJ, Gertler FB. Ena/VASP proteins: regulators of the actin cytoskeleton and cell migration. Annu Rev Cell Dev Biol 2003;19:541-64

Krugmann S, Jordens I, Gevaert K, Driessens M, Vandekerckhove J, Hall A. Cdc42 induces filopodia by promoting the formation of an IRSp53:Mena complex. Curr Biol 2001;11:1645-55

Lindsay SL, Ramsey S, Aitchison M, Renne T, Evans TJ. Modulation of lamellipodial structure and dynamics by NO-dependent phosphorylation of VASP Ser239. J Cell Sci 2007;120:3011-21

Madaio MP. Renal biopsy. Kidney Int 1990;38:529-43

Maruyama K, Yoshida M, Nishio H, Shirakawa T, Kawamura T, Tanaka R, Nakamura H, lijima K, Yoshikawa N. Polymorphisms of renin-angiotensin system genes in childhood IgA nephropathy. Pediatr Nephrol 2001;16:350-5

Nakanishi K, Sako M, Yata N, Aoyagi N, Nozu K, Tanaka R, lijima K, Yoshikawa N. A-20C angiotensinogen gene polymorphism and proteinuria in childhood IgA nephropathy. Pediatr Nephrol 2004;19:144-7

Oh J, Reiser J, Mundel P. Dynamic (re)organization of the podocyte actin cytoskeleton in the nephrotic syndrome. Pediatr Nephrol 2004;19:130-7

Philippar U, Roussos ET, Oser M, Yamaguchi H, Kim HD, Giampieri S, Wang Y, Goswami S, Wyckoff JB, Lauffenburger DA, Sahai E, Condeelis JS, Gertler FB. A Mena invasion isoform potentiates EGF-induced carcinoma cell invasion and metastasis. Dev Cell 2008;15:813-28
Reiser J, Oh J, Shirato I, Asanuma K, Hug A, Mundel TM, Honey K, Ishidoh K, Kominami E, Kreidberg JA, Tomino Y, Mundel P. Podocyte migration during nephrotic syndrome requires a coordinated interplay between cathepsin $L$ and alpha3 integrin. J Biol Chem 2004;279:34827-32

Rose DM. The role of the alpha4 integrin-paxillin interaction in regulating leukocyte trafficking. Exp Mol Med 2006;38: $191-5$

Rosner B. The calculations are the customary ones based on the normal approximation to the binomial distribution. In Fundamentals of biostatisticsed^eds), 1995, Section 10.7, Mass: Duxbury, Boston

Srivastava T, Garola RE, Whiting JM, Alon US. Synaptopodin expression in idiopathic nephrotic syndrome of childhood. Kidney Int 2001;59:118-25

Tang S, Lai KN. Ultrasound-guided Biopsy of Native and Transplanted Kidneys. Saudi J Kidney Dis Transpl 2004; $15: 300-4$

Urbanelli L, Massini C, Emiliani C, Orlacchio A, Bernardi G. Characterization of human Enah gene. Biochim Biophys Acta 2006;1759:99-107

Vanderzalm P, Garriga G. Losing their minds: Mena/VASP/ EVL triple knockout mice. Dev Cell 2007;13:757-8

Yanagida-Asanuma E, Asanuma K, Kim K, Donnelly M, Young Choi H, Hyung Chang J, Suetsugu S, Tomino $Y$, Takenawa T, Faul C, Mundel P. Synaptopodin protects against proteinuria by disrupting Cdc42:IRSp53:Mena signaling complexes in kidney podocytes. Am J Pathol 2007;171:415-27 